\title{
STD/HIV intervention and research programme Mwanza Region, NW Tanzania
}

\section{J Changalucha, A Gavyole, H Grosskurth, R Hayes, D Mabey}

Sex Transm Infect 2002;78(Suppl I):i91-i96

The social determinants and epidemiology of sexually transmitted disease (STD) were studied in rural communities in Mwanza Region, Tanzania, in the context of the phase specific model of STD transmission. The prevalence of HIV and syphilis was higher in communities close to main roads, and lower in communities living on islands in Lake Victoria, probably reflecting the proportion of high risk individuals in the population. The prevalence of Herpes simplex virus type 2 infection, gonorrhoea, chlamydial infection, and trichomoniasis was similar in all types of community, reflecting the fact that these infections remain in the hyperendemic phase. The transmission of STDs is fuelled by high population mobility and by the presence of high risk individuals in rural as well as roadside communities.

See end of article for authors' affiliations

Correspondence to:

Correspondence to:
Professor David Mabey Department of Infectious and Tropical Diseases, London School of Hygiene and Tropical Medicine,

Keppel St, London

WCIE 7HT, UK;

david.mabey@|shtm.ac.uk

Accepted

30 November 2001
M wanza Region stretches along the southern shores of Lake Victoria, the largest of the African lakes, and includes the Ukerewe Island archipelago. The area is situated 190-360 km south of the equator, on a plateau about $1100 \mathrm{~m}$ above sea level. The region extends about $260 \mathrm{~km}$ from east to west and up to $170 \mathrm{~km}$ from north to south. The landscape is semiarid and comprises mostly cultivated bushland, small areas of marshland, and patches of forest. During the rains, many villages become inaccessible, and even the main long distance truck routes may occasionally be blocked for some days.

\section{Population structure and key demographic data \\ Ethnicity}

The region is almost entirely occupied by ethnic groups of Bantu origin, the Sukuma being the most numerous. Other ethnic groups from neighbouring regions and other parts of Tanzania including Indians and Arabs, can be found in Mwanza town and in centres along the main roads, Each ethnic group has its own language, but Kiswahili is the official national language.

\section{Religion}

About $70 \%$ of the population in Mwanza town are Christians, 20\% are Moslems, and 10\% hold other religious beliefs. ' In rural areas of Mwanza Region, the corresponding figures are $76 \%, 5 \%$, and $29 \%{ }^{2}$
Population distribution

The region had about 1.8 million inhabitants in 1988, ${ }^{1}$ and about 2.5 million inhabitants in 1999 , based on a population growth rate of $2.6 \%$ per annum. ${ }^{3}$ The population in Mwanza town grows faster than that in rural areas (about $8 \%$ per annum), from around 200000 people in 1988 to almost 500000 by 1999 . The region also has six semiurban centres with a population of about 20000 each, serving as district administrative headquarters. The great majority of the population lives in rural villages or in communities with widely scattered compounds. (A compound is a group of houses occupied by one or more families, and surrounded by their farm land.)

\section{Important demographic data}

The total fertility rate in Mwanza Region has been estimated at around 6.9. ${ }^{3}$ Life expectancy at birth is 46 years for women and 50 years for men. Under-five child mortality was 137/1000 live births during the five years preceding 1996. The age and sex composition of the population is typical of those with high growth rates, with almost $50 \%$ of the population under 15 years of age. The density of population averages $71 / \mathrm{km}^{2}$, but varies in rural areas, depending on local soil fertility. The Ukerewe archipelago is the most densely populated rural district of Tanzania.

\section{Mobility and migration}

The population of Mwanza town is growing faster than that of rural areas, mainly because of net migration from rural to urban areas. Even the rural population is rather mobile. For example, in the regional survey of 1990/91, 7\% of men and $16 \%$ of women reported that they had immigrated into the study communities during the previous two years. ${ }^{4}$ Twenty six per cent of the study population seen during the baseline survey of the Mwanza trial reported that they had lived elsewhere during the previous five years, and more than $40 \%$ of men and about $30 \%$ of women reported having travelled outside their district of residence at least once during the past 12 months. ${ }^{5}$ After two years of follow up, $14 \%$ of the study cohort were lost to follow up because they had migrated out of the community. ${ }^{6}$

The close links that Mwanza has with other countries provided safe haven for refugees from several places in times of distress. In 1994, about half a million Rwandese refugees entered the neighbouring Kagera Region within a few weeks following the events during and after the genocide in Rwanda. Most returned to Rwanda in 1996, but a few thousand remained in Tanzania, settling in Mwanza and other large towns of the 
country, joining the refugees from other neighbouring countries who have settled in the area since the early 1960s.

\section{Education}

Almost all children attend primary school for some time. Rates of schooling are higher in Mwanza town than in rural parts of the region. Most communities have a primary school. The adult literacy rate in Mwanza is about $60 \%$. Nationwide, $61 \%$ of men and women aged 20 to 24 years completed primary school, and 13\% of young men and $8 \%$ of young women completed secondary school.

Overview of the social, political, and economic situation The rural population of the region lives mostly on subsistence farming. Cotton and maize are the main cash crops. Inhabitants of the lake shore communities and of the Ukerewe islands engage in fishing, farming, or both. Some gold mining is carried out in the western part of the region, partly under government auspices and partly by small scale miners. In recent years, foreign companies have increasingly engaged in the gold mining industry and these developments are likely to bring about major changes in terms of demography, economics, and sexually transmitted disease (STD) epidemiology in the years to come. Some industrial development has occurred in Mwanza town over the past 10 years, comprising fish processing factories, boat yards, a cotton ginnery, a textile factory, and two breweries.

Mwanza town is a major traffic centre, situated at the junction of two important truck and bus routes that link Central Africa with Kenya and the coastal parts of Tanzania. Mwanza is connected with the capital, Dar es Salaam, by rail and road, and by shipping lines across the lake with the neighbouring Kagera Region and with Uganda and Kenya. The town has an airport, offering regular flights to Dar es Salaam, Arusha, Zanzibar, Nairobi, and Entebbe.

The gross national product (GNP) of Tanzania is US\$241 per capita. Most families live on less than US\$150 a month. Based on these figures, Tanzania is one of the world's most disadvantaged countries. However, GNP data do not fully reflect the value of farm products in an economy that to a large extent relies on subsistence, and GNP data are also not suitable for measuring some of the political and social achievements that are characteristic of the country.

From 1964 until now, a socialist government has been ruling the country, originally based on a one party system. During the 1990s, many political and social changes occurred. The principle of multiparty democracy has been introduced, some of the administrative powers have been decentralised, foreign currency regulations have been liberalised, the economy has been opened to foreign enterprises, and a "structural adjustment" process has been initiated under the influence of the International Monetary Fund, leading to a "mixed economy". While these developments increased trade, industrial investment, and government revenue, and led to more wealth for some parts of the population, they were also associated with an increase in foreign economic influence, an increase in poverty for a large proportion of the population, and a widening economic gap between the poor and the rich. However, the country has so far enjoyed peace and stability, and is blessed by a large degree of harmony between its different ethnic groups.

\section{NATURE OF SEXUAL NETWORKS: SEXUAL BEHAVIOUR \\ Commercial sex}

Most of the following observations are based on unpublished experience from the African Medical and Research Foundation (AMREF) "high transmission area" and "bar girl" intervention projects which operated for almost a decade.
Commercial sex work is not legalised in Tanzania, but tolerated without much interference by the police or other authorities. This attitude facilitates the implementation of intervention programmes. Where sex work exists, it is not labelled as such. In Mwanza Region, commercial sex is often provided by bar girls and guesthouse attendants, for whom sex work provides additional income. Although there is some stigma attached to commercial sex, most sex workers are ready to admit that they engage in it, and are open to intervention efforts if these avoid further stigmatisation.

The number of sex workers in Mwanza town has been estimated at around 1500. They operate in and from hotels, guesthouses, bars, and around shops that sell local alcoholic beverages (the so called pombe shops). Similar establishments can be found in the district headquarters, in bus and truck stops along the two major highways, and in the mining areas. The number of clients is usually restricted to two or three a week, although sex workers around the mines have reported up to 10 clients a night.

There is anecdotal evidence of a much more clandestine variety of sex work, whereby some women in the general population in Mwanza town and at truck stops engage in commercial sex on an occasional basis. This sector is much more difficult to reach through intervention activities. Both forms of commercial sex are poverty driven, although the increased availability of luxury goods and the lack of cash among the less advantaged majority of the population contributes to prostitution.

From an interventionist point of view, it is important to realise that local and Western concepts concerning commercial sex differ to some extent. While genuine commercial sex work clearly exists, not all exchange of sex for money or goods is perceived as "prostitution", and many men and women involved would feel offended if their sexual activity were labelled as such. Much of it could be better described as an exchange of favours, mutual assistance, and friendliness.

Clients of sex workers include truck drivers, travellers, and miners but also local residents. During a sexual behaviour survey, only $2 \%$ of men from rural communities admitted to having sex with a bar girl or sex worker during the past year. ${ }^{2}$ Because during such surveys rural men seem to be comparatively open about their sexual activity, it is likely that this information is credible. However, there is evidence that also in rural areas there are groups of highly promiscuous women, although these are much more difficult to identify than genuine sex workers.

There is no evidence of homosexual commercial sex, or sex work driven by drug addiction.

\section{Non-commercial sex}

\section{Data sources}

Much information on self reported sexual behaviour in the general population of rural Mwanza has been collected through a series of population based studies conducted between 1991 and 1995, in the context of the Mwanza STD/HIV intervention trial which involved about 12500 adults aged 15 to 54 years. ${ }^{67}$ Sexual behaviour data were collected through in-depth interviews of a representative subsample of about 700 men and 800 women from the trial cohort. ${ }^{2}$

\section{Marriage patterns}

In the Mwanza cohort, which was a representative sample of the population aged 15 to 54 years from 12 large study communities, $68 \%$ of men were married, $5 \%$ were presently divorced or widowed, and $27 \%$ had never married (these comprised mostly young men). For women, these figures were $81 \%, 11 \%$, and $9 \%$, respectively. Fourteen per cent of married men and $24 \%$ of married women lived in polygamous relationships. At the age of 20 , about $75 \%$ of the women, but only $25 \%$ of the men, were married. At the age of 25 years 
these figures were $95 \%$ and $65 \%$, respectively. In this study, the definition of "marriage" included both formal marriages and other long lasting stable partnerships. Marital dissolution and remarriage were common in both sexes. Thirty six per cent of men and 33\% of women had been widowed or divorced at least once.

\section{Sexual debut}

Early sexual activity was common, with about $50 \%$ of women and $46 \%$ of men reporting first sexual intercourse before the age of 16 years. Only $8 \%$ of men and $6 \%$ of women had not started sexual activity by the age of 20 years. Because first marriage took place at a later age in men than in women, the mean interval between sexual debut and first marriage was shorter for women than for men ( 1.8 years $v 6.1$ years). Comparing women of different age groups, age of sexual debut and age at first marriage appear to have increased significantly over the past two to three decades. For men, no such trend was observed.

\section{Number of sexual partners}

Twenty eight per cent of men but only $2 \%$ of women reported 20 or more lifetime partners. Referring to the previous year, $29 \%$ of men but only $3 \%$ of women reported three or more partners, while $47 \%$ of men and $89 \%$ of women reported no more than one partner. Not having had a sexual partner at all during the last year was reported by $25 \%$ of men and $24 \%$ of women aged $15-19$ years, and $21 \%$ of women above 45 years. In all other age groups, not having had a sexual partner at all was reported by a small minority.

\section{Casual sex partners}

Fifty three per cent of men but only $15 \%$ of women admitted at least one casual partner during the past year (a single sexual contact or relationships lasting no more than a few weeks). Only $2 \%$ of men reported contacts with "bar girls".

\section{Comments}

Most men and women are in a stable marital union (including stable long term partnerships). However, a substantial proportion of men and women become widowed, divorced, or separated at some stage, and often marry again within a short time. This, along with polygamous marriage, implies that most will have multiple sexual partners during their lifetime, even within the marriage union. It is equally clear that many individuals, particularly men, have additional premarital and extramarital partners.

There was marked heterogeneity of behaviour between individuals, as indicated in particular by the large variance to mean ratio for the number of partners reported by men. Only $29 \%$ of men reported three or more partners during the past year, but these accounted for more than $60 \%$ of all partners reported in the population.

There was also a marked imbalance in the number of partners reported by men and women: the total number of partners reported by all men was about twofold higher than that reported by all women. In a closed population these two figures should roughly match. Possible explanations are that men had additional partners outside the study population (for example, while travelling away from the village), that women underreported the number of their partners, or that there are women within the communities who had multiple sex partners but who were missed by the survey, because of refusal to participate or because of high mobility. While there appears to be no formal prostitution in these rural communities, there is evidence from recent anthropological research that small groups of highly promiscuous women indeed exist in many rural communities.

\section{Sexual practices and other determinants of sexual health \\ Condom use}

At baseline, $88 \%$ of men and $63 \%$ of women in the trial cohort had heard of condoms, but only $20 \%$ of men and $3 \%$ of women had ever used one. Although condoms were available at health facilities in all villages, and although they were promoted to both the general population and individually to many STD patients during the STD intervention, condom uptake was low throughout the 1990s. For example, only about $1 \%$ of patients with genital discharge and genital ulcers accepted the condoms offered to them in the intervention health facilities. There is anecdotal evidence that condom uptake is now slowly increasing in rural communities.

\section{Other sexual practices}

Bruising during sex at any time in the past was reported by $23 \%$ of men and $10 \%$ of women. The practice of "dry sex", involving the insertion of herbs or other substances into the vagina, was reported by only $1 \%$ of the women. Ten per cent of men and women had heard of anal sex occurring in their community, but the frequency of this practice is not known.

\section{Circumcision}

During a general population survey in Mwanza Region conducted during 1990/1991, 16.3\% of rural men, 30.6\% of men in roadside settlements, and $59.0 \%$ of urban men reported that they were circumcised. ${ }^{4}$ In the trial cohort in rural Mwanza, 19\% of the men were circumcised. ${ }^{5}$ In the factory cohort in Mwanza town this proportion was $47 \% .{ }^{8}$ Male circumcision is more common in urban and semiurban than in rural populations, and in all of these strata it is more common in Muslims, but it also occurs in non-Muslims. Female circumcision is thought to be uncommon in Mwanza Region.

\section{PUBLIC HEALTH ORGANISATION AND INFRASTRUCTURE}

Mwanza town also has one teaching hospital, one regional, and two private hospitals. An STD reference clinic was integrated into the outpatient department of the regional hospital (Sekou Toure Hospital) in 1990. An STD clinic has also been established at the Makongoro Centre, the largest antenatal clinic of Mwanza town. Both STD clinics serve as reference and training units and have been the venue for several of the studies mentioned in this paper.

Regional health services are supervised by the regional medical officer (RMO). The regional AIDS control coordinator (RACC) is responsible for AIDS and STD control activities. During the 1990s, a regional STD intervention officer was appointed and seconded to AMREF. The RMO reports both to the regional administrative authorities and to the Ministry of Health.

The region has seven districts, Mwanza Municipality being one of them. At each of the six rural district headquarters, there is a district hospital. The region also has three mission hospitals. Public health services in each district are supervised by a health management team, headed by the district medical officer. Issues of AIDS control are addressed by the District AIDS control coordinator (DACC), who is mainly expected to organise educational activities. Unfortunately, owing to limited funds and the lack of transport, the DACC's outreach capacity is very limited. In the context of the Mwanza STD intervention trial, a new cadre was created to reinforce the district health management teams, the so called district STD control coordinator (DSCC).

The majority of the rural population depend on the services of health centres and dispensaries. Some dispensaries are run by mission health services, but most are government facilities. In total, the region has 23 functioning rural health centres and about 150 dispensaries. 
A health centre is staffed by about eight to 12 trained personnel and is managed by a clinical officer (CO). A dispensary has two to three trained staff and is led by an assistant clinical officer (ACO). Both cadres have a formal training of three years, but the CO is usually a secondary school leaver. A health centre usually has a bed capacity of 20 to 25 beds for inpatients, while a dispensary may have about three beds for short time observations, used in particular after deliveries. The drug supply for health centres and dispensaries is based on prepacked standardised kits as part of the national essential drug programme (EDP).

Dispensaries do not have laboratory facilities. Some but not all health centres are staffed by a laboratory technician, and are equipped with a microscope. However, there is no system for quality control, the equipment is often damaged, and the supply of reagents irregular.

In Mwanza town and in the district headquarters, there are several registered private medical practitioners, but during most years of the last decade hardly any such practitioners could be found in rural communities. The same applies to pharmacies. Traditional healers still play a substantial role in health care in both urban and rural areas. Nevertheless, government health facilities are the main source of treatment for STDs in rural communities of Mwanza Region. For example, in the regional survey of 1990/91, 71\% of men and $61 \%$ of women with STDs sought treatment from government health facilities, $19 \%$ of men and $32 \%$ of women from traditional healers, and $13 \%$ of men and $8 \%$ of women from other sources. ${ }^{9}$

\section{DESCRIPTION OF THE STD INTERVENTION PROGRAMME}

The STD intervention programme in Mwanza Region comprises different activities. As part of the Mwanza trial, a programme was launched from 1991 onwards to improve STD case management in rural health facilities. After successful completion of the trial, the programme was extended to many more health facilities in Mwanza town, in the region and in neighbouring regions. Targeted interventions were established to reach high risk groups in Mwanza town and in truck stops situated along the highways within Mwanza Region and neighbouring regions.

Both intervention packages were launched within the frame of the collaborative arrangements between AMREF, the Government of Tanzania, the Tanzanian National Institute for Medical Research (NIMR) and the London School of Hygiene and Tropical Medicine (LSHTM). In this paper we will focus on these intervention packages. However, TANESA and several mission organisations also support STD control efforts through a variety of activities in the region, for example as part of the research work in a cohort of factory workers, or through support provided to district health services or in mission hospitals. The approaches used in all the above programmes are largely standardised.

\section{STD intervention programme integrated into the general health services}

Details of the improved STD case management provided in rural health centres, and the methods used to measure the impact of improved services on the incidence and prevalence of HIV and other STDs, have been described previously. ${ }^{5-7}$ At the end of the trial, the intervention continued in all the intervention communities, and was extended to the six comparison communities, and to other communities of the region and four neighbouring regions thereafter. The same intervention was also introduced to the various health services established in refugee camps which exist in the neighbouring regions of Kagera and Kigoma.

After 1996, the supply of STD drugs for all regions participating in the national STD control programme was reorganised and centralised. Drugs were centrally purchased and distributed from Dar es Salaam. Soon afterwards, the drug supply to the region became erratic, and from 1997 onwards peripheral health facilities repeatedly ran out of STD drugs for many months.

\section{Impact and cost-effectiveness}

The Mwanza trial showed that improved STD services led to a significant reduction in HIV incidence at the population level (the rate of new infections in intervention communities was about $40 \%$ lower than in comparison communities). The intervention also significantly reduced the prevalence of active syphilis (TPHA+; RPR titre $\geqslant 1: 8$ ) by $33 \%$, the incidence of new infections of active syphilis by $44 \%$, and the incidence of symptomatic urethritis by $49 \%$, the latter results achieving only borderline significance. The intervention was shown to be highly cost-effective in the prevention of HIV infection: costs per disability adjusted life year (DALY) saved were about US\$11, and this calculation did not yet consider benefits that were generated because of the prevention of STD related morbidity.

\section{STD intervention for high risk groups in Mwanza town and truck stops}

A "high transmission area" intervention programme was established as of 1994 in truck stops in Mwanza Region, and later covered five regions of NW Tanzania. Activities included the provision of improved STD services through existing local health facilities, education through meetings and written materials, condom promotion, and condom supply through a variety of outlets. The target population comprised hotel, guest house and bar owners, bar girls and guesthouse attendants, truck drivers, and other transport workers.

\section{STD AND HIV EPIDEMIOLOGY Data sources}

During the STD/HIV intervention trial, AMREF, NIMR, and LSHTM investigated the prevalence and incidence of HIV infection and the prevalence of various STDs in a cohort of 12550 adults aged 15 to 54 years (referred to as the "Mwanza trial cohort" in the remainder of this paper). The cohort was recruited from eight rural, two roadside, and two island communities in Mwanza Region. The studies were performed between 1991 and 1995. They included a baseline survey and a follow up survey conducted two years later, ${ }^{5610-12}$ two consecutive cross sectional surveys of about 1000 pregnant women from the same 12 communities ("the first and second rural antenatal clinic (ANC) studies"11 ${ }^{13}$ ). A detailed study of STDs in about 1000 men living in one large roadside settlement was conducted in $1996 .{ }^{14}$ Data on STD syndromes were collected from 25 rural health centres and dispensaries during the trial. ${ }^{15}$

\section{Syphilis/general and ANC population}

In the Mwanza trial cohort, the baseline prevalence of active serological syphilis was $7.8 \%$ in men and $9.1 \%$ in women (TPHA+/RPR+, any titre). In the two roadside settlements, these prevalences were higher (about $10.0 \%$ and $12.0 \%$, respectively). If the definition of active syphilis was restricted to RPR titres of $\geqslant 1: 8$, the overall prevalence was $6.2 \%$. Serological markers for present or past syphilis (TPHA+) were found in $14.5 \%$ of men and $16.5 \%$ of women. The incidence of TPHA seroconversion over two years of follow up was $4.1 \%$ in communities without intervention, and new cases of active syphilis (TPHA+/RPR $\geqslant 1: 8$ ) were found in $3.4 \%$ of the studied population in these communities. In the first rural ANC study, the prevalence of active syphilis (TPHA+/RPR $\geqslant 1: 8$ ) was $8.0 \%$ ( $10.1 \%$ for any RPR titre). 


\section{HSV-2 infection/general population}

In the Mwanza trial cohort, HSV-2 infection was determined using a type specific enzyme linked immunosorbent assay (ELISA) test. HSV-2 prevalence was already $18 \%$ in girls aged 15 years and rose steeply with age to about $75 \%$ in women more than 25 years old. None of the men was infected before age 17, but prevalence in men increased steadily with age to about $60 \%$ in those older than 30 years. ${ }^{12}$

Reported genital ulcers: general and ANC population In the baseline survey of the Mwanza trial cohort, 15\% of men and $5.6 \%$ of women reported having had a genital ulcer at least once, and clinically confirmed ulcers were seen in $1.4 \%$ of the men and $0.8 \%$ of the women. In the first and second rural ANC studies, $0.7 \%$ and $0.3 \%$ of women had a clinically confirmed ulcer.

\section{Trichomoniasis: general and ANC population}

In the rural ANC study, $27.4 \%$ of women were infected with Trichomonas vaginalis. ${ }^{13}$. In a roadside community, $11 \%$ of 1004 male inhabitants were infected with $T$ vaginalis, and less than $50 \%$ of these complained of discharge or dysuria. ${ }^{14}$

\section{Gonorrhoea, chlamydial infection, and urethritis: general and ANC population}

In the Mwanza trial cohort, men were screened for urethral symptoms and for pyuria with a leucocyte esterase dipstick. Subjects with symptoms or a positive test result were examined, and urethral swabs were taken for detection of $N$ gonorrhoeae by Gram stain and for $C$ trachomatis by antigen detection immunoassay. Because of this strategy, the data reported here represent minimum prevalences. At baseline, $2.2 \%$ of the men had gonorrhoea and $0.7 \%$ had chlamydial infection. Of those infected, only $15 \%$ complained of urethral discharge. Confirmed non-specific urethritis (non-gonococcal and non-chlamydial) was found in $7.6 \%$ of the men, but only about $10 \%$ of these had symptoms. ${ }^{11}$

Using culture and Gram stain on cervical smears to detect gonorrhoea and an antigen detection immunoassay to detect chlamydial infection, $2.1 \%$ of pregnant women from the rural ANC study were diagnosed with $N$ gonorrhoeae, and $6.6 \%$ with C trachomatis; $8.4 \%$ had either of these infections. ${ }^{13}$

\section{Candidiasis and bacterial vaginosis: general and ANC population}

In the rural ANC study, $14.3 \%$ of women had vaginal candidiasis. Bacterial vaginosis was not investigated in the trial or in the ANC study, but a prevalence of $44 \%$ was found among unselected women attending a rural general outpatient clinic (Mayaud P, personal communication).

\section{HIV-1 infection: general population}

In the baseline survey of the trial cohort, the prevalence of HIV infection was $3.4 \%$ in men and $4.2 \%$ in women from rural communities. Island communities had significantly lower prevalences ( $1.8 \%$ among both men and women) and roadside communities significantly higher prevalences $(7.5 \%$ and $7.9 \%$, respectively). The incidence of HIV infection over two years was $1.9 \%$ in communities without improved STD services, equivalent to an annual incidence of $0.95 \%$. The incidence was lower in communities which had access to improved STD treatment services and which were exposed to educational campaigns promoting prompt treatment for STDs $(1.2 \% v$ $1.9 \%) .^{56}$

\section{STD/RTI syndromes in rural STD patients}

The rural health unit study, conducted during the Mwanza trial, showed that almost 13000 syndromic episodes were diagnosed and treated over two years. ${ }^{15}$ There were similar numbers of cases in men and women. In men, the most common syndromes were urethral discharge $(67 \%)$ and genital ulcers $(26 \%)$. In women they were vaginal discharge $(50 \%)$, lower abdominal pain (33\%, treated as suspected pelvic inflammatory disease), and genital ulcers (13\%). Other syndromes-including buboes without ulcer, balanitis, suspected secondary syphilis, genital warts, epididymitis, and pubic lice-were relatively uncommon. STD patients were treated syndromically. There was no laboratory to investigate the aetiology of reproductive tract infections and STD. ${ }^{611}$

\section{RELEVANCE TO THE PHASE SPECIFIC MODEL}

Epidemics of sexually transmitted infections evolve through predictable phases, shaped by a dynamic interplay between the pathogen, the behaviours of the subpopulations in which they emerge, and the prevention efforts that are developed to limit their impact. ${ }^{16}$ In planning appropriate control strategies for particular STDs in particular populations, it is important to consider the phase which the epidemic has reached.

The HIV epidemic seems to have stabilised in Mwanza town by the early 1990s, with an almost constant prevalence of around $11 \%$ in pregnant women. In the early 1990s HIV prevalence was still rising in rural communities, from about $2.5 \%$ in the regional survey of $1990 / 91$ to about $3.7 \%$ in 1992 . The incidence in the trial cohort was about $1 \%$ a year in the early 1990s in communities without the STD intervention. With a mortality rate of around $10 \%$ per year in HIV positive individuals, ${ }^{17}$ new infections greatly exceeded those lost because of deaths. During the trial, HIV incidence in intervention communities was substantially lower. HIV prevalence in former intervention communities remained at about $4 \%$ among adults in 2001 (Ross D, personal communication), implying either that the HIV epidemic has generally reached a plateau at this level in rural communities, or that the ongoing STD intervention has a lasting effect on HIV incidence and prevalence. The latter explanation would be consistent with predictions derived from computer modelling. ${ }^{18}$

Given this apparent stability in HIV prevalence in rural communities, it is likely that the higher prevalence in roadside and urban communities reflects the fact that these contain a greater proportion of high risk individuals, although the possibility that roadside and urban communities are at an earlier phase of the HIV epidemic cannot be excluded. The fact that the prevalence of markers for syphilis, which has long been endemic, was higher in roadside settlements (about $22 \%$ ) than in rural communities (about 13\%) supports the former conclusion.

A comparatively low syphilis prevalence was observed in lake island communities, with a rate of about $8.5 \%$ for past or present syphilis. HIV prevalence was also low (1.7\%). Again, this probably reflects a smaller proportion of high risk individuals in these communities, as a smaller number of life time partners was reported by island men than by their mainland rural counterparts ( $\geqslant 5$ partners: $59 \% \vee 75 \%$ ), and a higher rate of circumcision ( $40 \% v 20 \%)$. However, there were no significant differences between communities for HSV-2 infection or male urethritis, or for the prevalences of gonococcal or chlamydial infection or trichomoniasis in pregnant women.

A possible interpretation is that HIV and syphilis are still more closely associated with "core group" patterns of sexual networking in these communities, while HSV-2 and nonulcerative STDs are more widely dispersed and less dependent on high risk behaviour.

An analysis of HIV infection within subclusters of roadside settlements showed that the prevalence was higher within the central parts of these communities than in peripheral clusters. It is likely that women in truck stops who have sexual contacts with truck drivers and other travellers are most likely to be found near the centre of these communities. In the early phase of the epidemic they may have functioned as a bridging population from which the epidemic slowly entered the rural 
population. In Mwanza town, HIV prevalence was much higher in bar girls than in the general population. Sexual contacts within high risk behaviour groups, and between subjects from this core group and the general population seem to play a major role in the spread of STDs and HIV infection in the town. Various other factors are also important, in particular the rather high mobility of the rural population as described in this paper, and the suspected existence of groups of men and women within rural communities who have many more partners than the average and thus act as a core group that enhances the spread of infection, even in the absence of overt commercial sex work.

Further research is needed on migration patterns and on sexual networks in these rural and periurban communities, to provide the evidence base on which to build appropriately targeted intervention strategies against HIV and other STDs.

\section{ACKNOWLEDGEMENTS}

The work summarised in this paper is largely based on data from published studies that were conducted by various collaborating institutions throughout the 1990s, including the National Institute for Medical Research (NIMR) Mwanza, the African Medical and Research Foundation (AMREF) Mwanza, the Government of Tanzania, and the London School of Hygiene and Tropical Medicine (LSHTM). Other partners in this collaboration were the Bugando Medical Centre (BMC), the Regional Hospital of Mwanza, and several mission hospitals within the region. Parts of this paper refer to studies in a cohort of factory workers that have been conducted by the Tanzania-Netherlands Project to Support AIDS Control (TANESA) in collaboration with NIMR, BMC, the Government of Tanzania, and the Royal Tropical Institute (KIT). We gratefully acknowledge the scientific input from all this work, especially the contributions of all those who contributed to the original field and laboratory work, in particular: Ezra Mwijarubi (AMREF), Edna Matasha (AMREF), Theonestina Ntembelea (AMREF), Philippe Mayaud (LSHTM), Beryl West (LSHTM), Mary Shushu (NIMR), and Jan Cornelissen (NIMR). We are grateful to Angela Obasi (AMREF), Richard White, Basia Zaba, and Jim Todd (all LSHTM) for their valuable assistance and comments during the preparation of this paper.

Financial support was provided by the European Commission, the Department for International Development (DFID) of the United Kingdom, the Medical Research Council of the UK, and the Centre for International Migration and Development (CIM) of the Federal Republic of Germany. Other donors included DANIDA, SIDA, and WHO. The work of TANESA was supported by the Government of the Netherlands. The government of Tanzania supports the National Institute and provides salary support to staff working in the various health facilities and to those who were temporarily seconded to research teams during field surveys.

\section{Authors' affiliations}

J Changalucha, National Institute for Medical Research, Mwanza, Tanzania

A Gavyole, African Medical and Research Foundation, Mwanza,
Tanzania

H Grosskurth, R Hayes, D Mabey, London School of Hygiene and

Tropical Medicine, Keppel Street, London WC1, UK

\section{REFERENCES}

1 Bureau of Statistics. Population census 1988, Mwanza regional profile. Dar es Salaam, Tanzania: President's Office and Planning Commission, 1992.

2 Munguti R, Grosskurth $\mathrm{H}$, Newell J, et al. Patterns of sexual behaviour in a rural population in North-Western Tanzania. Soc Sci Med 1997;44:1553-61.

3 Bureau of Statistics. Tanzania demographic and health survey, August 1997. Dar es Salaam, Tanzania: President's Office and Planning Commission, 1997

4 Barongo L, Borgdorff M, Mosha F, et al. The epidemiology of HIVinfection in urban areas, roadside settlements and rural villages in Mwanza Region, Tanzania. AIDS 1992;6:1521-8.

5 Grosskurth H, Mosha F, Todd J, et al. A community trial of the impact of improved STD treatment on the HIV epidemic in rural Tanzania. 2. Baseline survey results. AIDS 1995;9:927-34.

6 Grosskurth H, Mosha F, Todd J, et al. Impact of improved treatment of sexually transmitted diseases on HIV Infection in rural Tanzania: randomised controlled trial. Lancet 1995;346:530-6.

7 Hayes R, Mosha F, Nicoll A, et al. A community trial of the impact of improved STD treatment on the HIV epidemic in rural Tanzania. 1. Design. AIDS 1995;9:916-26.

8 Barongo L, Borgdorff $M$, Newell J. Intake of a cohort study of urban factory workers in Northwest Tanzania. Trop Geogr Med 1994:46: 157-62.

9 Newell J, Senkoro K, Mosha F, et al. A population-based study of syphilis and sexually transmitted disease syndromes in north-western Tanzania. 2. Risk factors and health seeking behaviour. Genitourin Med 1993;69:421-6.

10 Grosskurth H, Mayaud P, Mosha F, et al. Asymptomatic gonorrhoea and chlamydial infection in rural Tanzanian men. BM 1996;312:277-80

11 Mayaud P, Mosha F, Todd J, et al. Improved treatment services significantly reduce the prevalence of sexually transmitted diseases in rural Tanzania: results of a randomised controlled trial. AIDS 1997; 1 1:1873-80.

12 Obasi A, Mosha F, Quigley M, et al. Antibody to herpes simplex virus type 2 as a marker of sexual risk behaviour in rural Tanzania. J Infect Dis 1999:179: 16-24.

13 Mayaud P, Grosskurth H, Changalucha J, et al. Risk assessment and other screening options for gonorrhoea and chlamydial infections in women attending rural Tanzanian antenatal clinics. Bull WHO 1995:73:621-30.

14 Watson-Jones D, Mugeye K, Mayaud P, et al. High prevalence of trichomoniasis in rural men in Mwanza, Tanzania: results from a population-based study. Sex Transm Inf 2000;76:355-62.

15 Grosskurth H, Mwijarubi E, Todd J, et al. Operational performance of an STD control programme in Mwanza Region, Tanzania. Sex Transm Inf 2000;76:426-36.

16 Wasserheit JN, Aral SO. The dynamic topology of sexually transmitted disease epidemics: implications for prevention strategies. J Infect Dis 1996; 174(suppl 2):S201-3.

17 Todd J, Balira R, Grosskurth H, et al. HIV-associated adult mortality in a rural Tanzanian population. AIDS 1997;1 1:801-7.

18 Korenromp EL, Van Vliet C, Grosskurth H, et al. Model-based evaluation of single-round mass treatment of sexually transmitted diseases for HIV control in a rural African population. AIDS 2000;14:573-93. 